\title{
Perspectivas de la reforma migratoria en Estados Unidos
}

Rodolfo García Zamora*

El proyecto de reforma migratoria propuesto por el gobierno de Barack Obama ha despertado much a controversia, tanto por quienes se oponen de manera definitiva en adoptar cualquier esquema de inclusión de los migrantes indocumentados, como por quienes detectan que el proyecto demócrata es insuficiente y además excluyente para la amplia comunidad de inmigrantes indocumentados que contribuye cotidianamente al desarrollo de Estados Unidos. El debate no ha terminado.

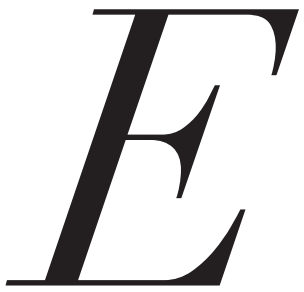

N UNA MESA REDONDA sobre las perspectivas de la reforma migratoria en Estados Unidos realizada en la $2^{\mathrm{a}}$ Feria del Libro en Español en Los Ángeles, California, en 2013, participaron los especialistas en migración México-Estados Unidos René Zenteno y Jorge Bustamante del Colegio de la Frontera Norte (Colef), Gaspar Rivera y Rubén Hernández de la Universidad de California (UCLA). En este documento se presenta lo más sustancial de la discusión en ese foro.

*Director de la Unidad Académica de Estudios del Desarrollo de la Universidad Autónoma de Zacatecas, México.
Para René Zenteno, nos encontramos en un ambiente favorable a la reforma migratoria debido a la tendencia demográfica latina y la votación favorable a Barack Obama. Sin embargo, los requisitos y tiempos (ı а ı5 años) considerados en el proyecto de reforma son excesivos: seguridad fronteriza más severa, endurecimiento del sistema de verificación de empleadores, fortalecimiento del sistema de registro de salidas del país, pago de multas e impuestos no pagados, programas de trabajadores agrícolas y de profesionistas de alta calificación y transición a residencia permanente y luego a ciudadanía.

El mismo investigador resalta la existencia de II millones de mexicanos en Estados Unidos (II\% de la población nacional) y el hecho de que la crisis de 2007- 
2013 ha significado un desplome de la emigración de 600 mil en 2007 a r8o mil en 2012, y cómo en 2010 se llegó a hablar de "migración cero" por el equilibrio entre la entrada, deportación y regreso de migrantes mexicanos. Posiblemente, cuando se recupere la economía estadounidense, volverá a crecer la emigración, pero por cuestiones demográficas, entre otras, no podrá volver a crecer como entre i994 y 2006. De hecho, para 205ॅ, la estructura de edades será similar entre México y Estados Unidos.

Entre ambos países se estaría experimentando una nueva era de la migración caracterizada por la reducción del flujo, disminución de aprehensiones en la frontera, deportaciones crecientes desde el interior y separación de miles de familias (85 mil). En ese sentido, el Pew Hispanic Center informa que hay 3.3 millones de menores de edad con padres indocumentados en Estados Unidos.

La criminalización de los inmigrantes deriva en la categorización de "removidos" a los migrantes detenidos y apercibidos judicialmente de que si reinciden serán condenados a prisión por cinco años; actualmente el número de inmigrantes en esta situación se ha incrementado para llegar a 300 mil. No obstante, ante las deportaciones masivas y el creciente encarcelamiento de los "removidos", el Estado mexicano ha permanecido inmóvil.

En este contexto, Zenteno hace tres pronunciamientos: I) es importante considerar cuál es el proyecto de país de Estados Unidos para mantener el liderazgo en la competencia mundial por los mercados y cómo se inserta la reforma migratoria y la atracción de diferentes migrantes para tal fin; 2) es necesario que el Estado mexicano asuma que la nación mexicana está constituida por más de i $\{5$ millones de personas, más allá de las fronteras, y que urge un cambio a fondo en el Estado, en su visión, estructura y funcionamiento que le permita cumplir con sus obligaciones en la defensa de los mexicanos en el exterior, y 3) en particular, el Estado mexicano no puede permanecer indiferente ante la deportación masiva de más de i.5 millones de migrantes durante el gobierno de Obama y el encarcelamiento de 3 oo mil por ser migrantes "removidos".

Gaspar Rivera señala que hay que construir la narrativa de la reforma migratoria. ¿. Se trata de villanos o víctimas?, ¿se trata de castigar o apoyar la obtención de la ciudadanía? Entre otros aspectos, esta tarea debe considerar el trasfondo demográfico entre ambos países que explica muchas de las actitudes políticas de demócratas, republicanos, empleadores, iglesias y otros actores. Actualmente, la población latina asciende a 52 millones de personas y para 205̆o representará $24 \%$ de la población (ro8 millones). De ese monto actual, el $65 \%$ es de origen mexicano. Un dato muy relevante es que $60 \%$ de la población latina es nacida en este país y sólo $40 \%$ es inmigrante. Su nivel de ingresos es muy parecido al de la población afroamericana, con $25 \%$ de la población en situación de pobreza. Políticamente, el $70 \%$ de los latinos votó por Obama. Sin embargo, de una población latina de 24 millones de votantes, sólo $50 \%$ ejerció el derecho al voto. Entre 2012 a 2030, la población latina votante crecerá $40 \%$, lo cual representa un referente para el mercado electoral estadounidense.

En el panorama actual, donde privan múltiples alianzas sociales en Estados Unidos a favor de la reforma migratoria, Rivera destaca a los dreamers, universitarios indocumentados que han eludido su expulsión del país y han revitalizado la lucha por la permanencia. Además observa la importancia de alianzas transnacionales que ayuden a la legalización y ciudadanización de II millones de migrantes irregulares en Estados Unidos.

Por su parte, Rubén Hernández plantea un enfoque pesimista sobre la reforma migratoria, pero destaca que estamos obligados a un "realismo con esperanza”. En esa lógica, a diferencia de 1986 , el actual proyecto de reforma se distingue porque existe una mayor criminalización; la "internalización de las fronteras", las redadas y persecuciones contra migrantes indocumentados se realizan en todas partes al interior del país; más restricciones y leyes contra los indocumentados; los costos, pagos y tiempos son exagerados para los migrantes que soliciten su regularización; además de que se podrían evitar las deportaciones con una estancia temporal condicionada, caracterizada por la alta precarización y la exclusión a los servicios de salud y otros.

En este marco, Hernández señala que el proceso de debate apenas comienza y habrá que esperar los resultados y efectos de la movilización y presiones de las organizaciones de migrantes y sus aliados, donde destacan los jóvenes de la primera y segunda generaciones, las instituciones académicas como la UCLA y otras que han apoyado las luchas por la legalización y los derechos plenos. En el caso mexicano, coincide en reconocer la ausencia del Estado y la falta de regulación de los programas de trabajadores y temporales H2A (en el campo) y H2B (otras actividades), por lo que se convierte en cómplice por omisión de la precarie- 
dad y sobreexplotación de los mexicanos que participan en esos programas al no cumplir ni la Constitución ni la Ley Federal del Trabajo.

Finalmente, Jorge Bustamente, decano de los migrantólogos en México, expresa su pesimismo sobre la reforma migratoria dado el complejo escenario actual donde destaca la mayor vulnerabilidad del proceso migratorio, el incremento de riesgos y violencias, el endurecimiento de la frontera, la crisis en Estados Unidos y el impacto en ambos países, entre otros factores. Coincide con los colegas anteriores acerca del exceso de costos, pagos y tiempos para los migrantes indocumentados propuestos en el proyecto de reforma - que había recibido más de 300 solicitudes de enmiendas por ambos partidos al inicio de mayo -, muchos migrantes no podrán cubrir todos esos requisitos. Su pesimismo es más estructural cuando señala que la reforma se realiza a partir del derecho de un país a definir su política migratoria y el ingreso de trabajadores extranjeros. Pero esa decisión unilateral no considera que el proceso migratorio, de hecho, es un fenómeno bilateral, con causas y efectos más allá de la frontera. Como la reforma no puede aplicarse más allá, no resolverá múltiples factores que tienen que ver con la migración entre ambos países. Finalmente, como los otros colegas, coincide en que el Estado mexicano ha sido omiso en proteger a los mexicanos en el extranjero y que urge un cambio a fondo en su actitud para cumplir la Constitución y ser garante de la defensa y los derechos en el exterior.
Los dreamers mexicanos en Estados Unidos son un sector de jóvenes universitarios indocumentados por el cual el gobierno mexicano nunca se ha preocupado ni hecho nada, pero representan una generación con mayor preparación académica, técnica, cívica y política, en un contexto de recesión económica prolongada donde se les discrimina y obstruye la inserción al mercado laboral estadounidense. Bustamante pronostica que ellos voltearán y descubrirán a México, y entonces podrán encontrar una oportunidad de trabajo y mejor vida gracias a la preparación recibida y las posibilidades que ofrece el país a jóvenes bilingües y bien preparados.

Como todo pronóstico, el anterior depende del cumplimiento de algunas variables, en este caso que se prolongue la recesión en Estados Unidos, que este país no siga con la estrategia anunciada de captar la mayor cantidad de talento en el interior y el exterior y que México pudiera insertarlos en un modelo económico extractivista, caracterizado por la exportación de materias primas, la maquila, el ensamble y la expulsión de ir millones de mexicanos de i970 a 2007, entre ellos 8 oo mil paisanos con un grado de licenciatura y más (se estima que hay i 5 mil doctores en ciencias mexicanos radicados en ese país).

Finalmente, Bustamante señala que confía más en la participación política de los mexicanos en Estados Unidos, que presentan mayor madurez y compromiso político, que en la de los mexicanos en México, que han hecho muy poco por defender a los migrantes en el exterior. 


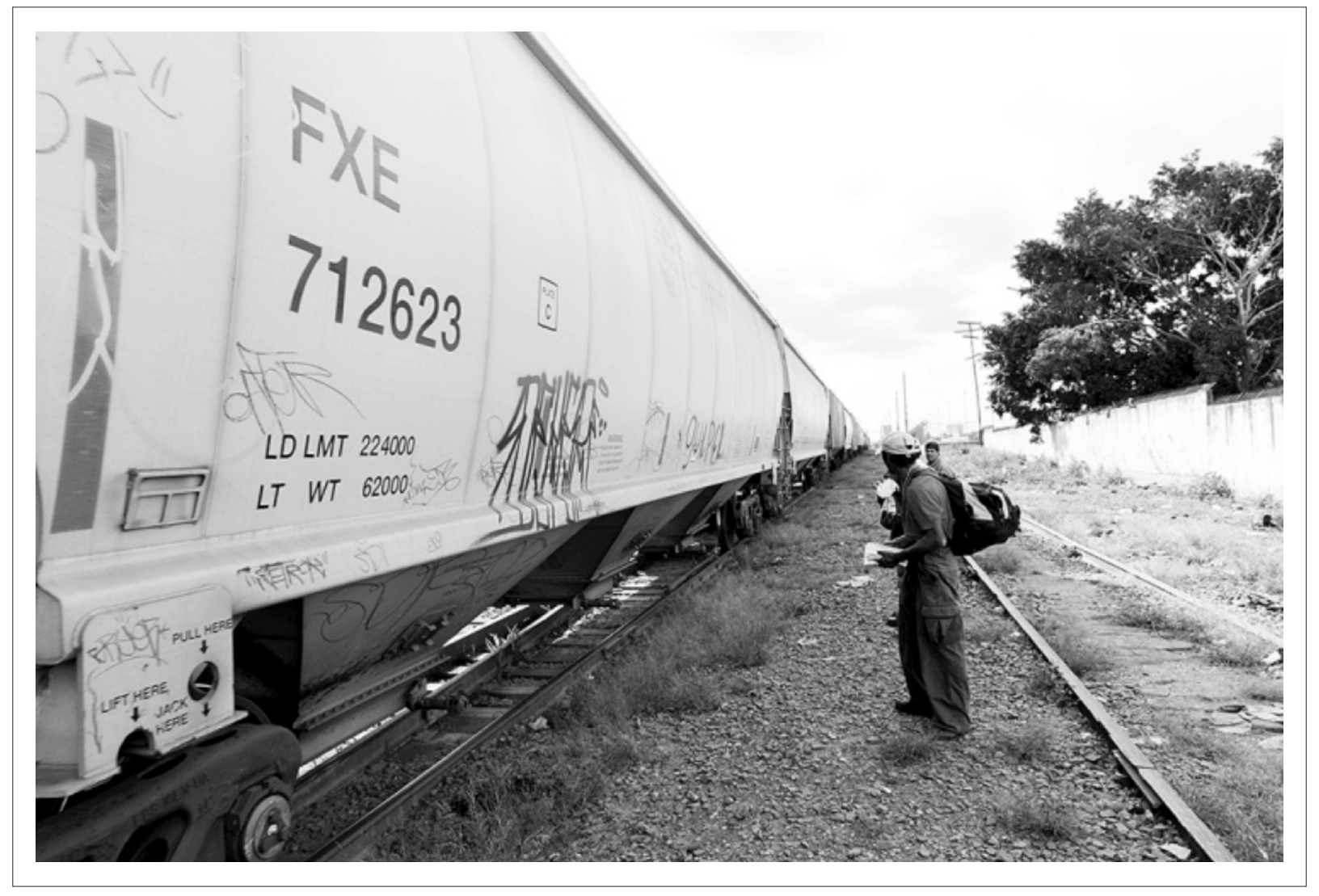

Foto: Óscar Fernández. Tomada en el Centro de Atención al Migrante (CAM), de FM4 Paso Libre. 